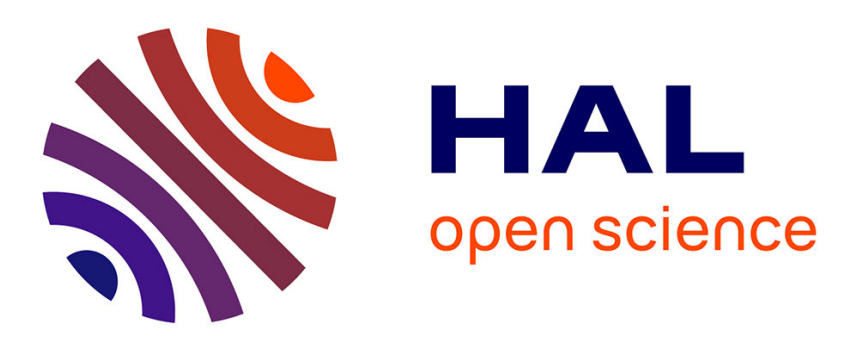

\title{
Theoretical Analysis of Brush Seals Leakage Using Local Computational Fluid Dynamics Estimated Permeability Laws
}

\author{
Lilas Deville, Mihai Arghir
}

\section{- To cite this version:}

Lilas Deville, Mihai Arghir. Theoretical Analysis of Brush Seals Leakage Using Local Computational Fluid Dynamics Estimated Permeability Laws. Journal of Engineering for Gas Turbines and Power, 2018, 140 (6), pp.062803. 10.1115/1.4038469 . hal-02304825

\section{HAL Id: hal-02304825 \\ https://hal.science/hal-02304825}

Submitted on 27 May 2021

HAL is a multi-disciplinary open access archive for the deposit and dissemination of scientific research documents, whether they are published or not. The documents may come from teaching and research institutions in France or abroad, or from public or private research centers.
L'archive ouverte pluridisciplinaire HAL, est destinée au dépôt et à la diffusion de documents scientifiques de niveau recherche, publiés ou non, émanant des établissements d'enseignement et de recherche français ou étrangers, des laboratoires publics ou privés.

\section{(c)(1)}

Distributed under a Creative Commons Attribution| 4.0 International License 


\title{
Theoretical Analysis of Brush Seals Leakage Using Local Computational Fluid Dynamics Estimated Permeability Laws
}

\author{
Lilas Deville \\ CNES, Direction des Lanceurs 75612 Paris/PPRIME Institute, UPR CNRS 3346 Université de Poitiers, ENSMA ISAE, Chasseneuil Futuroscope \\ 86962, France
}

Mihai Arghir

PPRIME Institute, UPR CNRS 3346 Université de Poitiers, ENSMA ISAE, Chasseneuil Futuroscope 86962, France

Brush seals are a mature technology that has generated extensive experimental and theo-retical work. Theoretical models range from simple correlations with experimental results to advanced numerical approaches coupling the bristles deformation with the flow in the brush. The present work follows this latter path. The bristles of the brush are deformed by the pressure applied by the flow, by the interference with the rotor and with the back plate. The bristles are modeled as linear beams but a nonlinear numerical algo-rithm deals with the interferences. The brush with its deformed bristles is then considered as an anisotropic porous medium for the leakage flow. Taking into account, the variation of the permeability with the local geometric and flow conditions represents the originality of the present work. The permeability following the principal directions of the bristles is estimated from computational fluid dynamics (CFD) calculations. A representative num-ber of bristles are selected for each principal direction and the CFD analysis domain is delimited by periodicity and symmetry boundary conditions. The parameters of the CFD analysis are the local Reynolds number and the local porosity estimated from the distance between the bristles. The variations of the permeability are thus deduced for each princi-pal direction and for Reynolds numbers and porosities characteristic for brush seal. The leakage flow rates predicted by the present approach are compared with experimental results from the literature. The results depict also the variations of the pressures, of the local Reynolds number, of the permeability, and of the porosity through the entire brush seal.

\section{Introduction}

As schematically represented in Fig. 1, brush seals consist of an annular pack of fine bristles mounted between two plates. The bristles are usually made of a cobalt-based alloy called Haynes 25 and its diameter is slightly less than a tenth of a millimeter. Other materials can be used, for example Kevlar. Brush seals are commonly used since the $1980 \mathrm{~s}$ in replacement of labyrinth seals because of their low leakage, low width, and compliance. Different modeling techniques have been used to simulate their behavior.

The first theoretical models introduced in the early $1990 \mathrm{~s}$ are semi-empirical approaches. Hendricks et al. [1,2] use empirical correlations to estimate the leakage flow of the seal and a simple mechanical model to compute the bristle's deformation. The model of Chupp et al. [3,4] is based on a coefficient similar to the friction factor for the pressure drop through a pipe, correlated with the thickness of the bristle pack. This kind of model, using rather simple physics, is easy to use and resource-efficient.

It was recognized early that the characteristics of the flow between the bristles is similar to the flow in an array of closely packed cylinders. Braun and Kudriavstev presented such in 1995 [5] with a two-dimensional (2D) computational fluid dynamics (CFD) analysis. This approach enabled a better understanding of the flow details inside the pack of bristles.

The latest modeling techniques use the fact that the brush can be represented as a porous medium. This technique does not require the complete computation of the flow between the bristles and for that reason it is employed by a large number of authors such as Chew et al. [6,7], Dogu [8], and Pröstler [9]. However, the method has the drawback that it relies on an a priori knowledge of the porosity and permeability generally estimated from experimental correlations. For this reason, modeling techniques using the porous medium approach have to be backed up with experimental data.

The modeling methods presented previously have two limitations. The first is that the strong coupling between the leakage flow and the deformation of the bristles of the brush is not taken into account. The second is that they rely on experimental data for the flow through the bristle pack.

The present study introduces a complete, fully coupled, multiphysics brush seal model based on the porous medium approach that does not rely on experimental data for the estimation of permeability and porosity. An iterative procedure between the deformation of the bristle pack and the calculation of the flow in a porous medium representing the brush is proposed in this paper. The porosity of the brush is estimated from the deformed bristles,

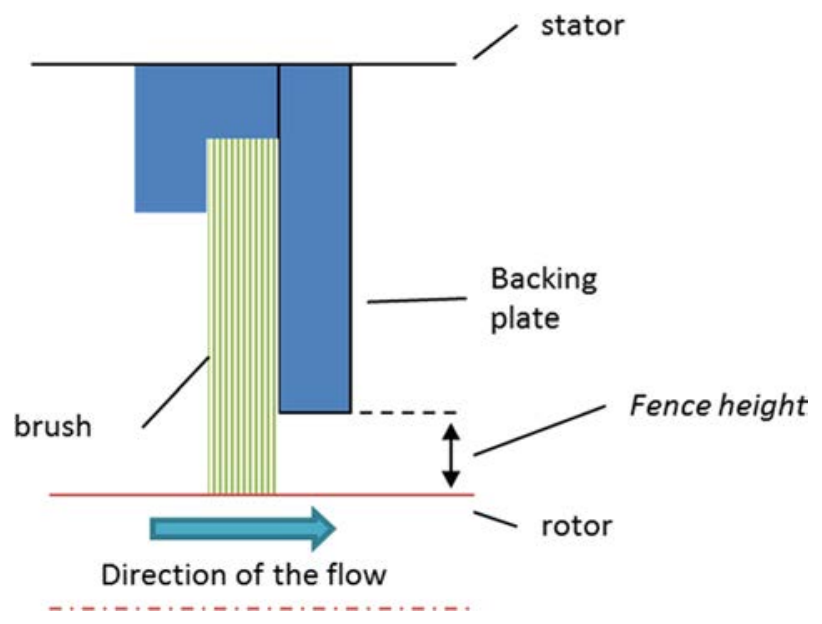

Fig. 1 Schematic representation of a brush seal 
and the permeability is obtained from CFD calculations of the pressure drop across different arrays of cylinders representative of the principal directions of the flow inside the brush.

\section{The Modeled Bristles Pack}

The complete modeling of the brush would require an excessive computational effort because the seal is composed of a very large number of bristles. Therefore, only a small part of the brush is modeled (Fig. 2), and the behavior of the seal will be deduced from periodicity boundary conditions. As the simulated cell is small in comparison with the whole brush, its curvature is neglected.

It is supposed that the bristles are in a hexagonal arrangement (Fig. 3) because it is the pattern that allows the highest compactness and is closest to the real lay out in a brush seal. The number of rows and columns characterizes the bristles pack: $i_{\max }$ is the number of rows that enables the application of periodicity boundary conditions and $j_{\max }$ is the number of columns deduced from the density of the brush per seal circumferential length.

Two coordinate systems depicted in Fig. 4 are used for analyzing the bristles pack. The $\mathbf{Z}$ axis of the global coordinate system $(\mathbf{X}, \mathbf{Y}, \mathbf{Z})$ is normal to the rotor and points radially outward. The $\mathbf{z}$ axis of the local coordinate system $(\mathbf{x}, \mathbf{y}, \mathbf{z})$ is aligned with the bristles direction. The axes $\mathbf{Y}$ and $\mathbf{y}$ are aligned with the main flow direction. The inclination of the bristles is $\phi$.

\section{The Deformation of the Bristles Pack}

The calculation of the bristles pack deformations is based on the method described by Guardino and Chew in 2005 [10]. Each bristle of the pack is modeled using the linear beam theory and is submitted to four different efforts:

(1) the forces due to the fluid flow pressure,

(2) the forces between contacting bristles,

(3) the contact forces between the bristle tip and the rotor, and

(4) the contact forces between the last row of bristles and the backing plate.

The bristles are discretized with equally spaced nodes as depicted in Fig. 5. No external force is applied at the clamping node, while at the tip node no fluid forces are applied.

Each node of the system is identified by a triplet $(i j k)$ where $i$ and $j$ indicate the row and the column of the bristle in the pack (Fig. 3) and $k$ is the number of the node along the bristle $i j$ (Fig. 5).

In each node, the total force is

$$
\mathbf{F}_{i j k}=\mathbf{R}_{i j k}^{\text {fluid }}+\mathbf{R}_{i j k}^{\text {bristles }}+\mathbf{R}_{i j k}^{\text {rotor }}+\mathbf{R}_{i j k}^{\text {backplate }}
$$

The deflection $\mathbf{f}_{i j k}$ at the node $(i j k)$ due to the application of the force $\mathbf{F}_{i j k}$ is

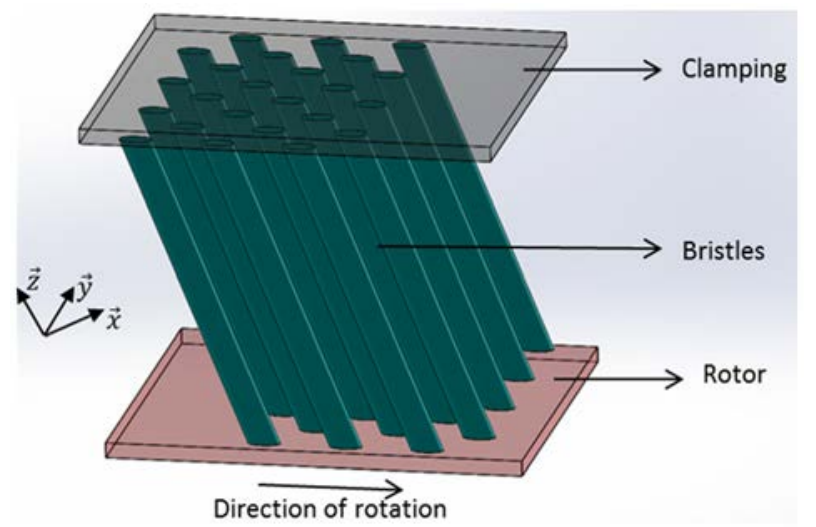

Fig. 2 Simplified representation of the simulated bristles pack

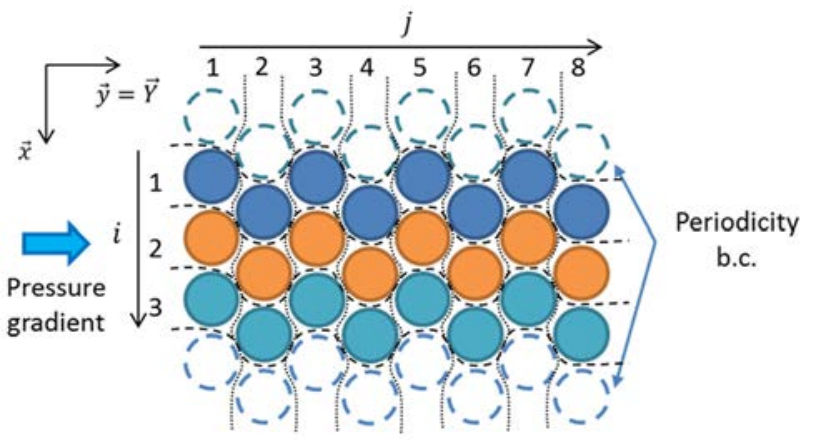

Fig. 3 Cross section of the simulated cell

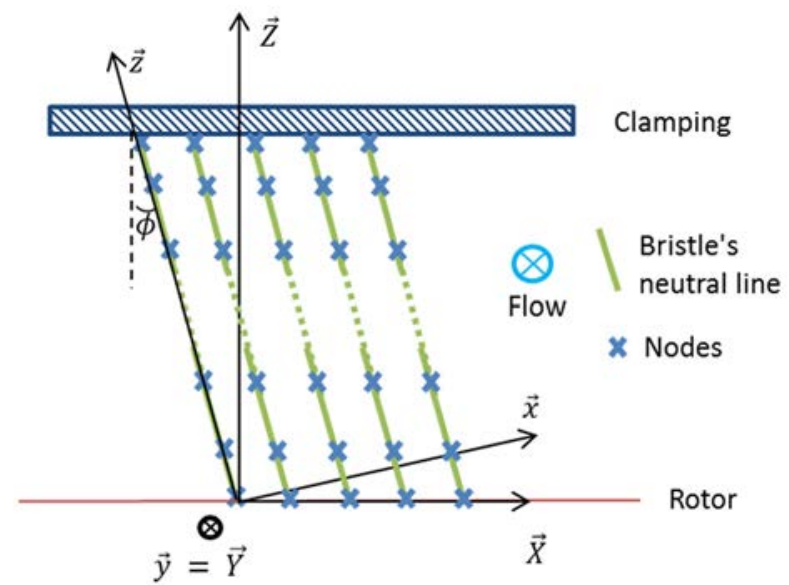

Fig. 4 Local and global coordinates systems

$$
\begin{gathered}
\mathbf{f}_{i j k}=\eta_{i j k} \mathbf{x}+\zeta_{i j k} \mathbf{y} \\
\eta_{i j k}=\frac{1}{E I_{z}} \sum_{m=1}^{k_{\max }} \tau_{k m} \mathbf{F}_{i j m} \mathbf{x} \\
\zeta_{i j k}=\frac{1}{E I_{z}} \sum_{m=1}^{k_{\max }} \tau_{k m} \mathbf{F}_{i j m} \mathbf{y}
\end{gathered}
$$

where

$$
\tau_{k m}= \begin{cases}\frac{\xi_{k}^{2} \xi_{m}}{2}-\frac{\xi_{k}^{3}}{6}, & 0 \leq \xi_{k}<\xi_{m} \\ \frac{\xi_{k} \xi_{m}^{2}}{2}-\frac{\xi_{m}^{3}}{6}, & \xi_{k} \leq \xi_{m}<L\end{cases}
$$

For simplicity, it is supposed that the contact between two neighboring nodes will only happen in a $Z=$ constant plane (Fig. 4). This means that the $k$ node of a $(i j)$ bristle can interact only with the same $k$ node of its neighboring bristles. It is possible

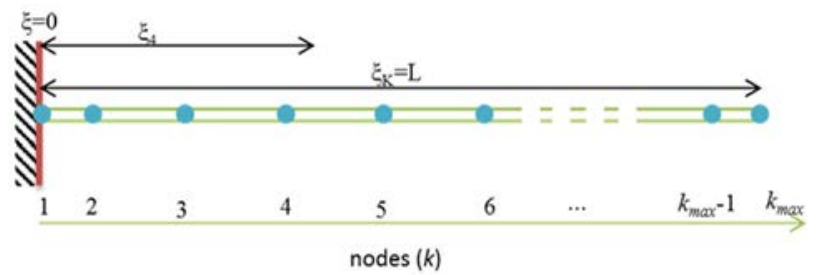

Fig. 5 Discretization of the bristles 


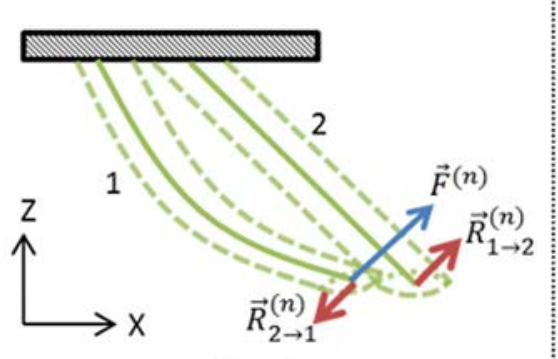

a-

Side view
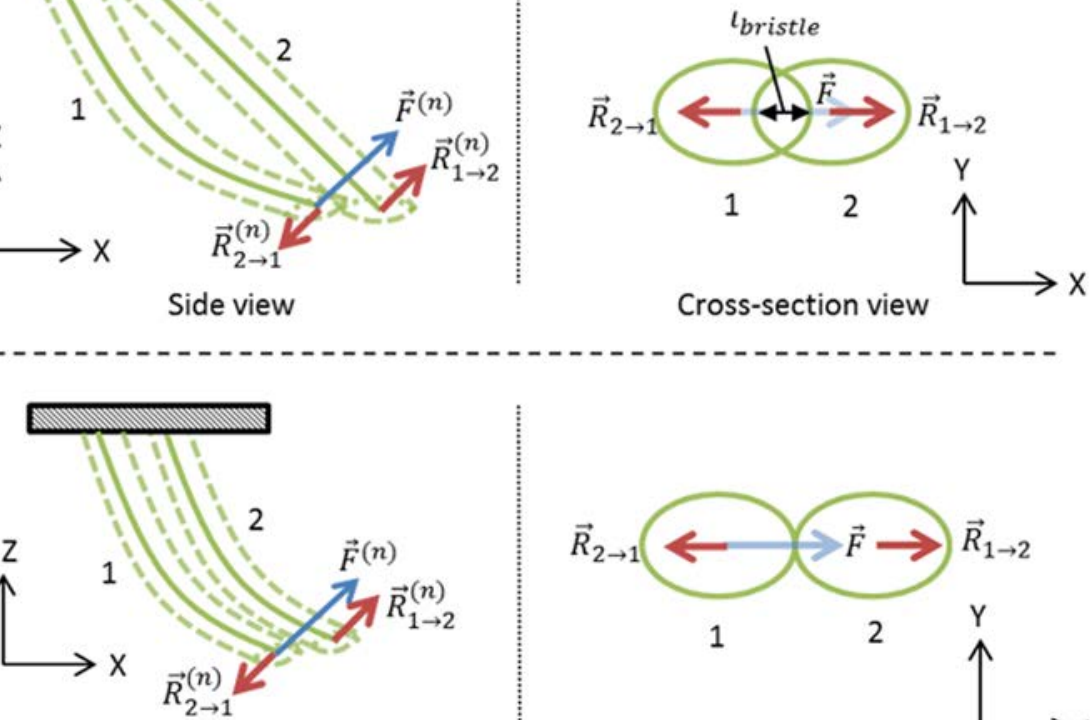

b-

Side view

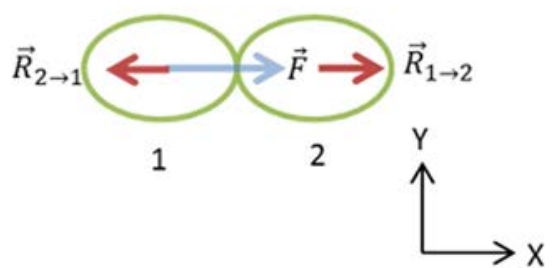

Cross-section view

Fig. 6 View of two interacting bristles: (a) interfering bristles before correction and (b) contacting bristles after correction

\section{Backing plate}

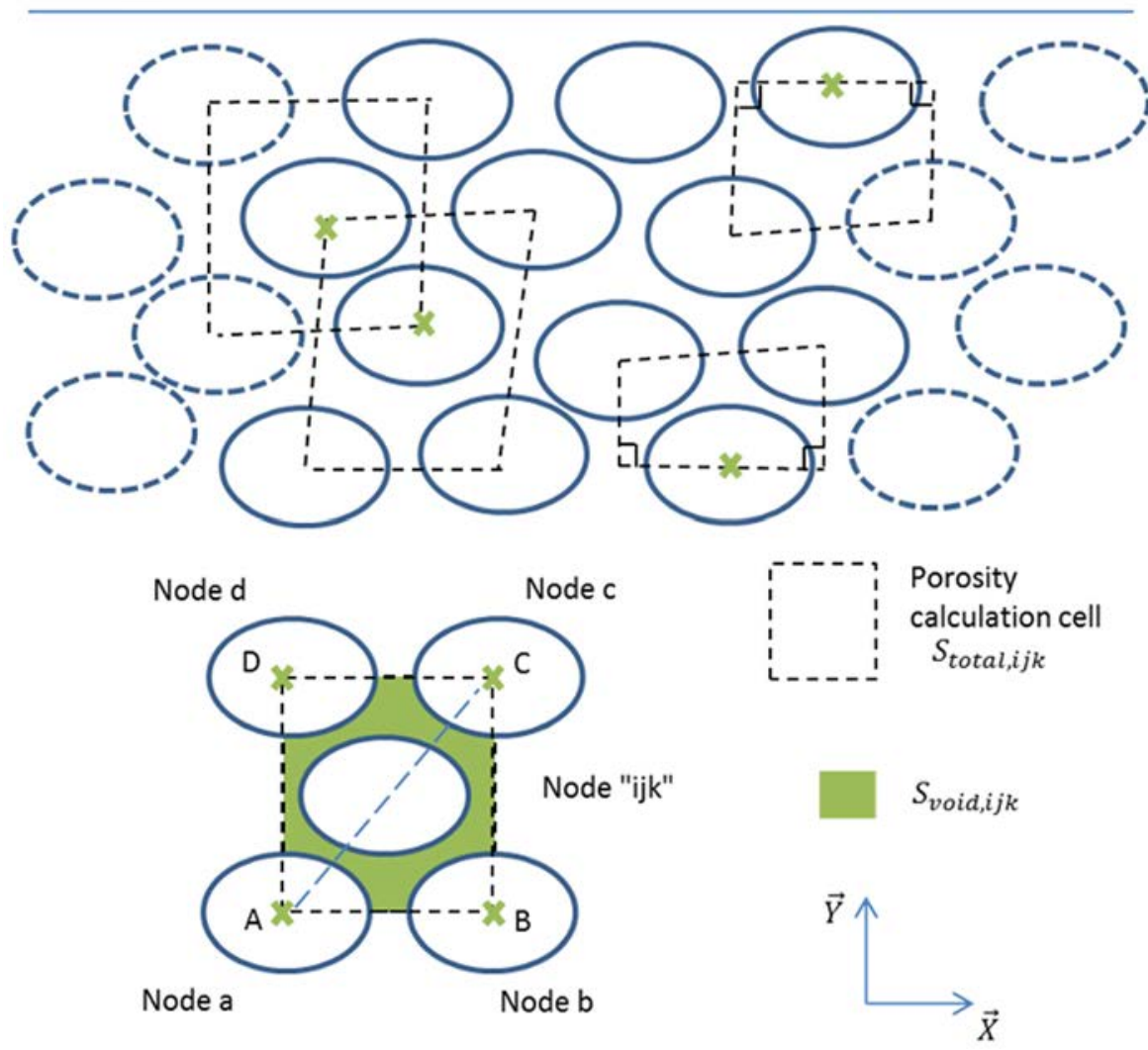

Fig. 7 Calculation of the brush porosity 


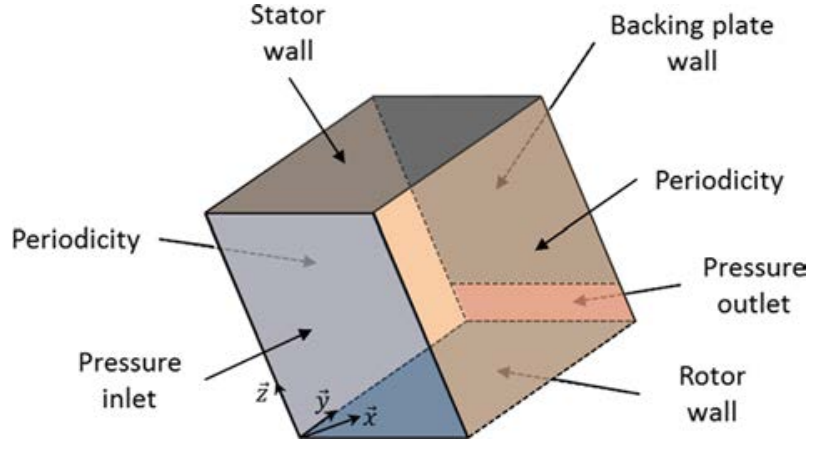

Fig. 8 Domain for the flow calculation

to make these approximations because the bristles deformations are small and the bristles are very closely packed.

The force due to the fluid flow $\left(\mathbf{R}_{i j k}^{\text {fluid }}\right)$ is estimated from the calculated pressure field in the porous medium and will be detailed later in this paper. The contact forces that might appear at nodes $\left(\mathbf{R}_{i j k}^{\text {bristles }}, \mathbf{R}_{i j k}^{\text {rotor }}\right.$ and $\mathbf{R}_{i j k}^{\text {backplate }}$ ) are iteratively computed from interferences between the bristles, the rotor, and the backing plate. All are obtained using the same algorithm that will be first described for the bristle contacts and then extended to the two others forces.

Bristle Contact Forces. Two bristles are in contact when the distance $s$ that separates their neutral lines is less than their diameter augmented by a parameter $e$ that takes into account their roughness. In 1996, Aksit and Tichy [11] use a roughness value of $1.2 \mu \mathrm{m}$ for brush seal bristles. This parameter will also be taken into account in the present work

$$
s<2\left(R_{\text {bristle }}+e\right)=2 R_{\text {contact }}
$$

During the computations, the fluid forces progressively deform the bristles that begin to interfere with each other (Fig. 6(a)). An appropriate deflection must then be applied to eliminate the interference noted $l_{\text {bristle }}$ in the $Z=$ constant plane and $l_{\text {bristle }}^{(n)}$ in the plane normal to the bristles (Fig. 6(b)). Each of the bristles must be given a displacement half the value of this interference. The bending theory of linear beams shows that corresponding deflection can be obtained when applying the following force to the bristle:

$$
\left|\mathbf{r}_{\text {bristle }}\right|=\frac{E I_{z}\left(l_{\text {bristle }}^{(n)} / 2\right)}{\tau_{k k}}
$$

where $\tau_{k k}$ is an element of the deformation tensor defined by Eq. (5).

The computation consists then in checking every node for interference with its neighboring nodes and then iteratively calculating the corrections for each of the contact forces using Eq. (7)

$$
\mathbf{R}_{\text {bristle }}^{\text {new }}=\mathbf{R}_{\text {bristle }}^{\text {old }}+\mathbf{r}_{\text {bristle }}
$$

Rotor and Backing Plate Contact Forces. The same algorithm is used to compute the contact forces between the bristles and the rotor or the backing plate. The only difference is that for these interactions only the bristles are displaced. The contact forces correcting the rotor and the back plate interferences are

$$
\begin{gathered}
\left|\mathbf{r}_{\text {backplate }}\right|=\frac{E I_{z} l_{\text {backplate }}}{\tau_{k k}} \\
\left|\mathbf{r}_{\text {rotor }}\right|=\frac{E I_{z} l_{\text {rotor }}}{\tau_{k k}}
\end{gathered}
$$

where $l_{\text {backplate }}$ and $l_{\text {rotor }}$ are the interferences between the bristle and the backing plate and the rotor, respectively.

\section{Porosity Calculation}

Once the brush is fully deformed, its spatially varying porosity can be computed from geometric considerations. A value of the

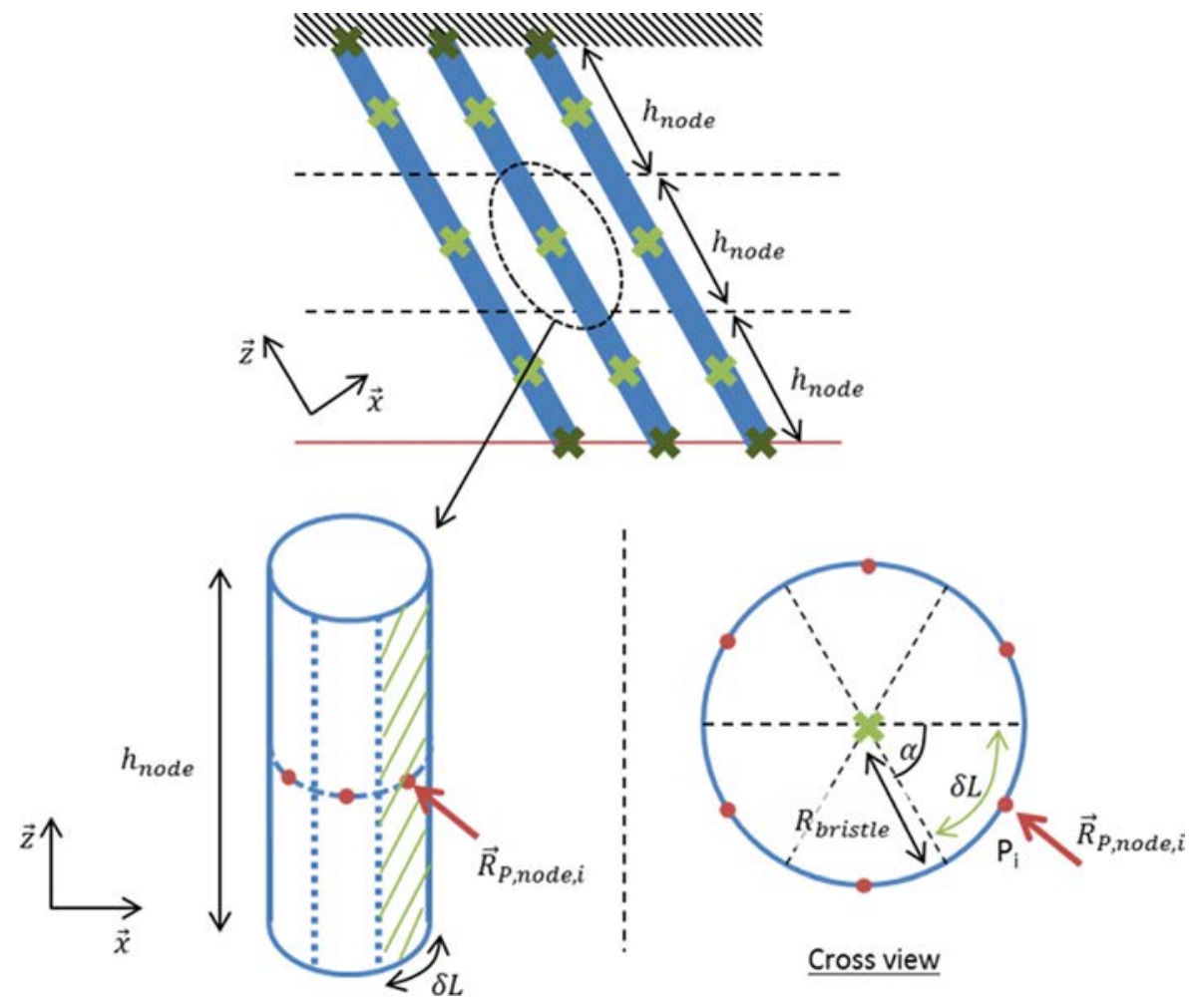

Fig. 9 Calculation of the pressure forces on the bristles 
porosity is associated with every node of the bristles pack and is calculated as depicted in Fig. 7

$$
\varepsilon_{i j k}=\frac{S_{\text {void }, i j k}}{S_{\text {total }, i j k}}
$$

In Eq. (11), $S_{\text {void, } i j k}$ is the surface of the void between the bristles, and $S_{\text {total }, i j k}$ is the total surface of the calculation cell.

\section{Calculation of Flow in the Porous Medium}

For calculating the leakage flow, the deformed brush is considered as a porous medium with known porosities. Darcy's equation describes the flow in a porous medium [12]

$$
-\frac{\Delta P}{\Delta L}=\frac{\mu}{K} u
$$

This equation relates the pressure gradient to the filtration velocity $u$ (the fluid velocity averaged over the section of the porous medium), the dynamic viscosity $\mu$, and the permeability $K$ of the porous medium. The permeability is an intrinsic characteristic of the porous medium that quantifies its ability to let the fluid flow.

Darcy's law is strictly valid for creeping flow but can be modified to take into account inertia effects that appear at higher velocities

$$
-\frac{\Delta P}{\Delta L}=a \mu u+b \rho u^{2}
$$

Following different references, it is known as Ergun's equation $[13,14]$ or Darcy-Forchheimer equation [15,16]; $a$ and $b$ are flow resistance coefficients, $a$ being the reciprocal of $K$. In 1952, Ergun introduced analytical definitions of $a$ and $b$ coefficients for a fibrous medium [13] depending on the porosity and on a characteristic diameter $D_{p}=1.5 D_{\text {bristle. A Reynolds number based on }}$ this diameter can be used to define the threshold when inertia effects became important in porous media flow [17,18], $\operatorname{Re}=\rho D_{p} u / \mu>40 \ldots 80$.

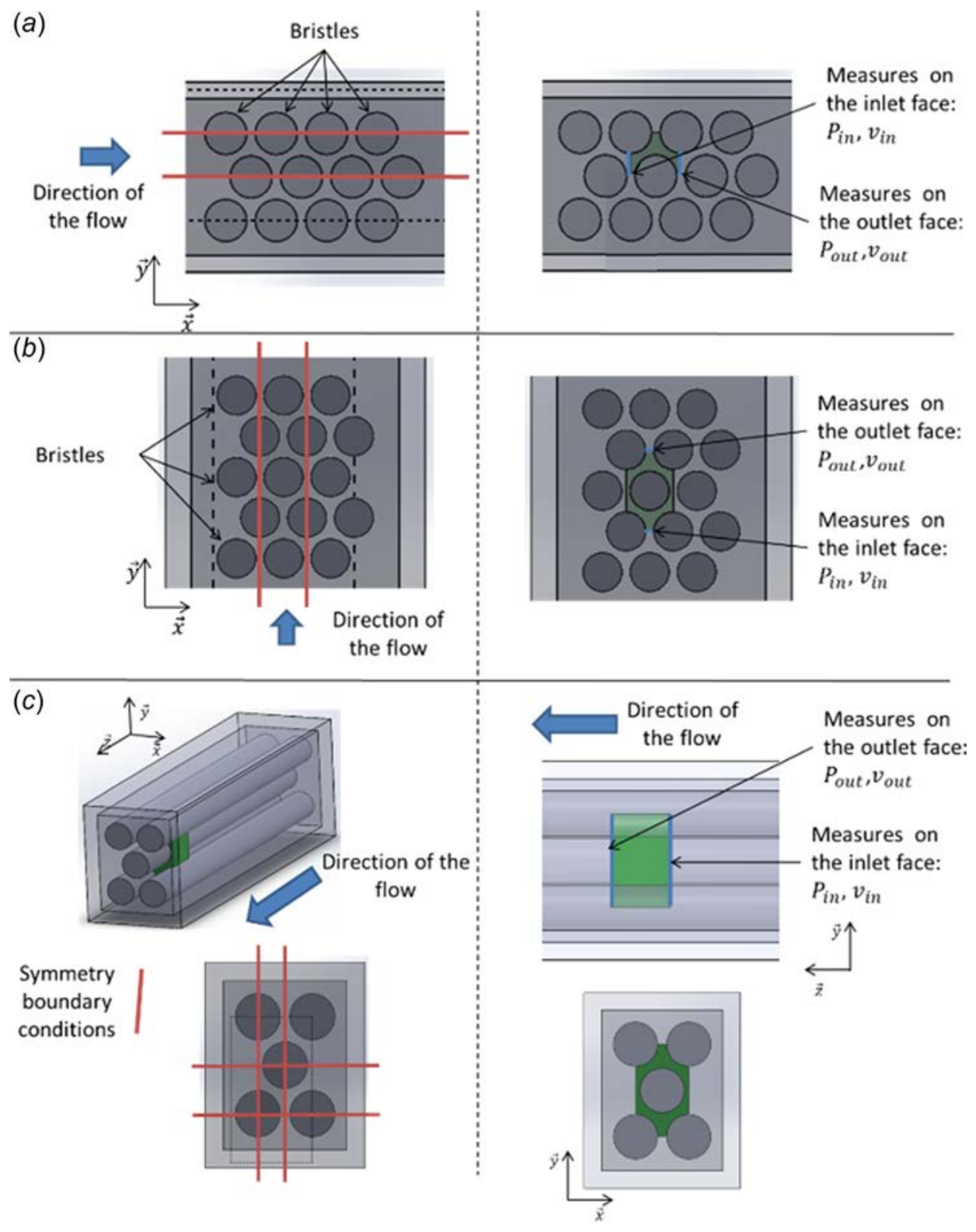

Fig. 10 Three CFD models for the pressure drop calculations along $x(a), y(b)$, and $z(c)$ axis 


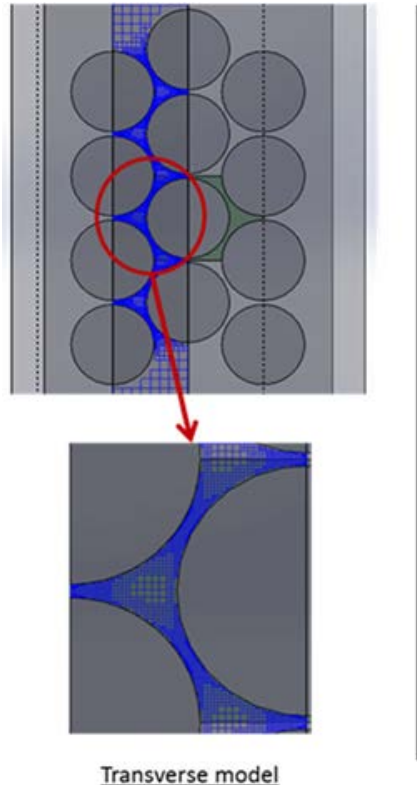

Transverse model

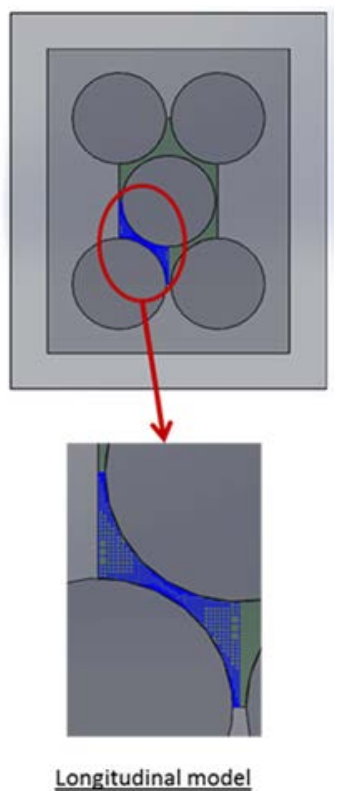

Longitudinal model

Fig. 11 Examples of meshes

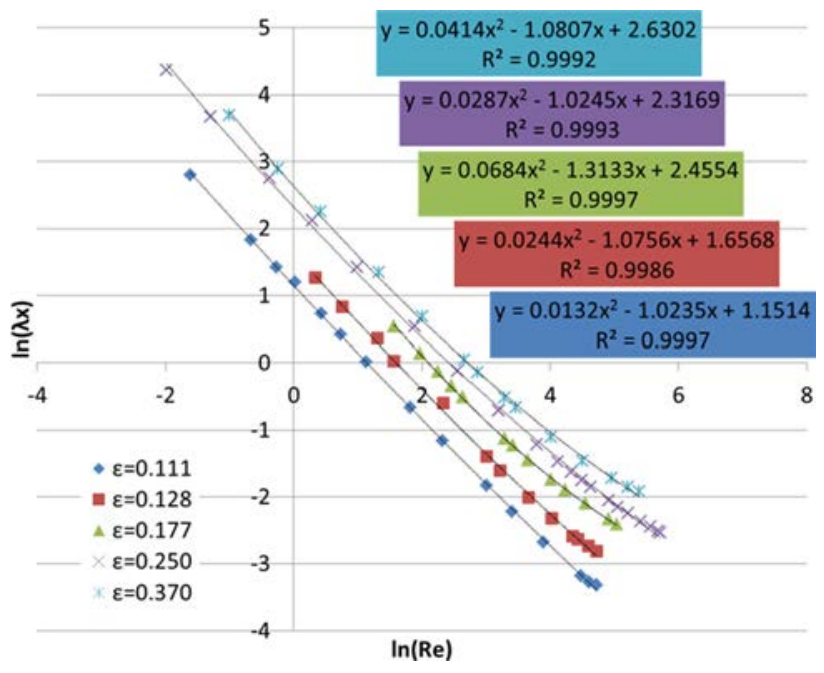

Fig. 12 Pressure drops along $\mathrm{x}$ axis

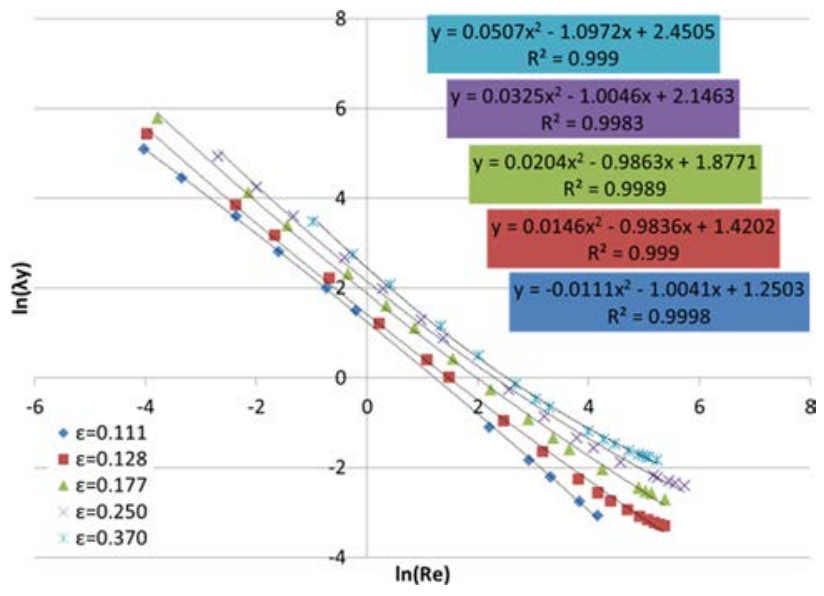

Fig. 13 Pressure drops along y axis

Equation (13) can be cast in a form similar to Eq. (12)

$$
-\frac{\Delta P}{\Delta L}=\mu\left(a+\frac{b \rho u}{\mu}\right) u=\frac{\mu}{K} u
$$

thus showing that the permeability $K$ of Eq. (14) is not a constant anymore when the viscous and inertia effects are of the same magnitude. A quasi-viscous equation of the flow in the porous media can then be used provided that the permeability depends on the porosity and on the local flow conditions, $K(\varepsilon, \mathrm{Re})$.

The continuity equation in a steady, compressible fluid is

$$
\frac{\partial\left(\rho u_{i}\right)}{\partial x_{i}}=0
$$

The momentum equations in a porous medium flow are

$$
\begin{gathered}
-\nabla P=\mu \mathbf{u} / K \\
K=1 /\left(a+\frac{b \rho|\mathbf{u}|}{\mu}\right)
\end{gathered}
$$

where convective terms were discarded and the influence of inertia forces is included via $K(\varepsilon, \mathrm{Re})$.

If the flow in the brush seal is isothermal and if the sealed fluid behaves as a perfect gas $(P=\rho \mathcal{R} T)$, then the density in Eq. (15) can be replaced by pressure. The filtration velocity $u_{i}$ is expressed by using the pressure gradient and the permeability $K$. This yields

$$
\frac{\partial}{\partial x_{i}}\left(K_{i j} P \frac{\partial P}{\partial x_{j}}\right)=0
$$

Equation (19) is solved on a hexahedral domain with the axes aligned to the principal directions of the bristles ( $\mathbf{x}, \mathbf{y}$ normal to the bristles, $\mathbf{z}$ pointing radially) shown in Fig. 8

$$
\frac{\partial}{\partial x}\left(\frac{K_{x x}}{\mu} P \frac{\partial P}{\partial x}\right)+\frac{\partial}{\partial y}\left(\frac{K_{y y}}{\mu} P \frac{\partial P}{\partial y}\right)+\frac{\partial}{\partial z}\left(\frac{K_{z z}}{\mu} P \frac{\partial P}{\partial z}\right)=0
$$

The anisotropic permeability $K_{i j}$ was numerically estimated as shown later in this paper. Equation (19) was solved by using the finite volume method adapted for skewed control volumes. Periodicity boundary conditions were used on the $\mathbf{x}$ planes. The pressure was imposed on the flow inlet and outlet faces aligned with the $y$ planes. Wall boundary conditions (i.e., zero flow rate) were used on the rest of the surfaces as indicated in Fig. 8. Once the

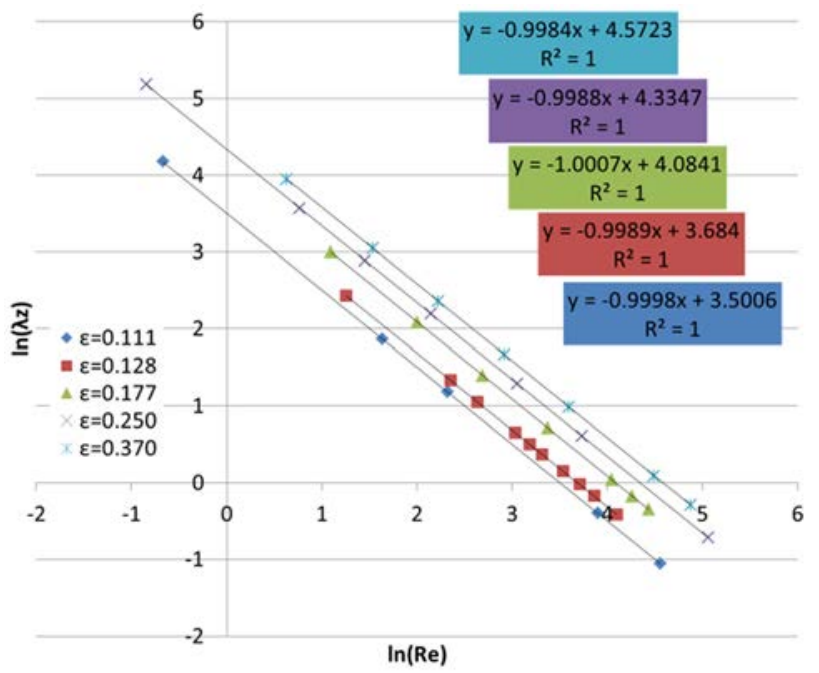

Fig. 14 Pressure drops along $z$ axis 

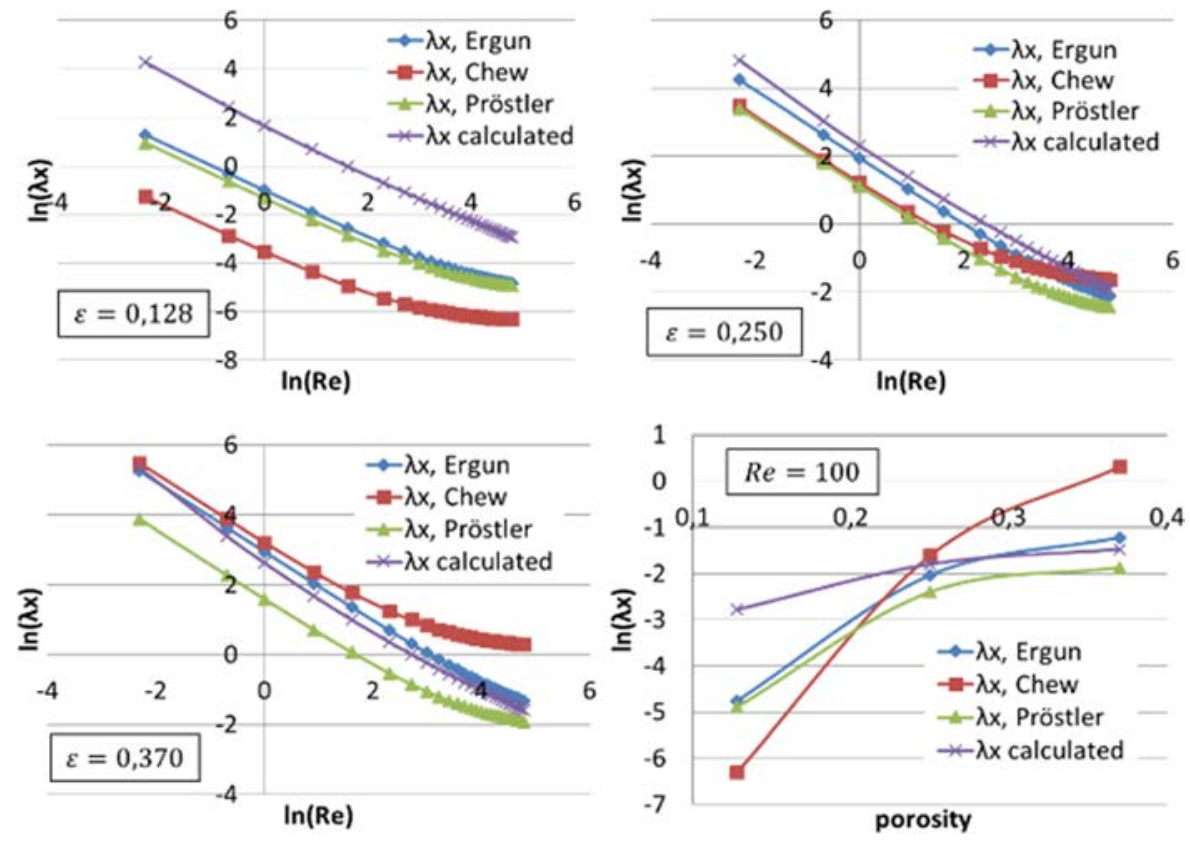

Fig. 15 Comparison of the calculated pressure drops along $x$ axis with the literature $[6,9,11]$

pressure field is calculated throughout the bristle pack, it is possible to deduce the forces that are applied by the fluid on the bristles. It is considered that the bristles are immerged in the three-dimensional (3D) pressure field calculated from the porous medium model. The pressures are then interpolated and integrated over the side area of each bristle's node as shown in Fig. 9.

\section{Numerical Calculation of the Permeability}

As stated in the introduction, a porous medium model requires the knowledge of the porosity and of the permeability. The porosity was previously calculated from geometrical considerations. For the permeability, Pröstler underlined in Ref. [9] the similarity between the Darcy's (12) and Darcy-Forchheimer equation (13) and the pressure drop in a duct

$$
\lambda=-\frac{\Delta P / \Delta L}{\rho v^{2} / d_{h}}
$$

where $\Delta L$ is the length of the porous medium. The relation between the filtration velocity $u$ and the mean velocity of the fluid between the bristles $v$ can be found from the mass flow rate

$$
q_{m}=S v=S_{f} u \Rightarrow v=\frac{S_{f}}{S} u=c_{v} u
$$
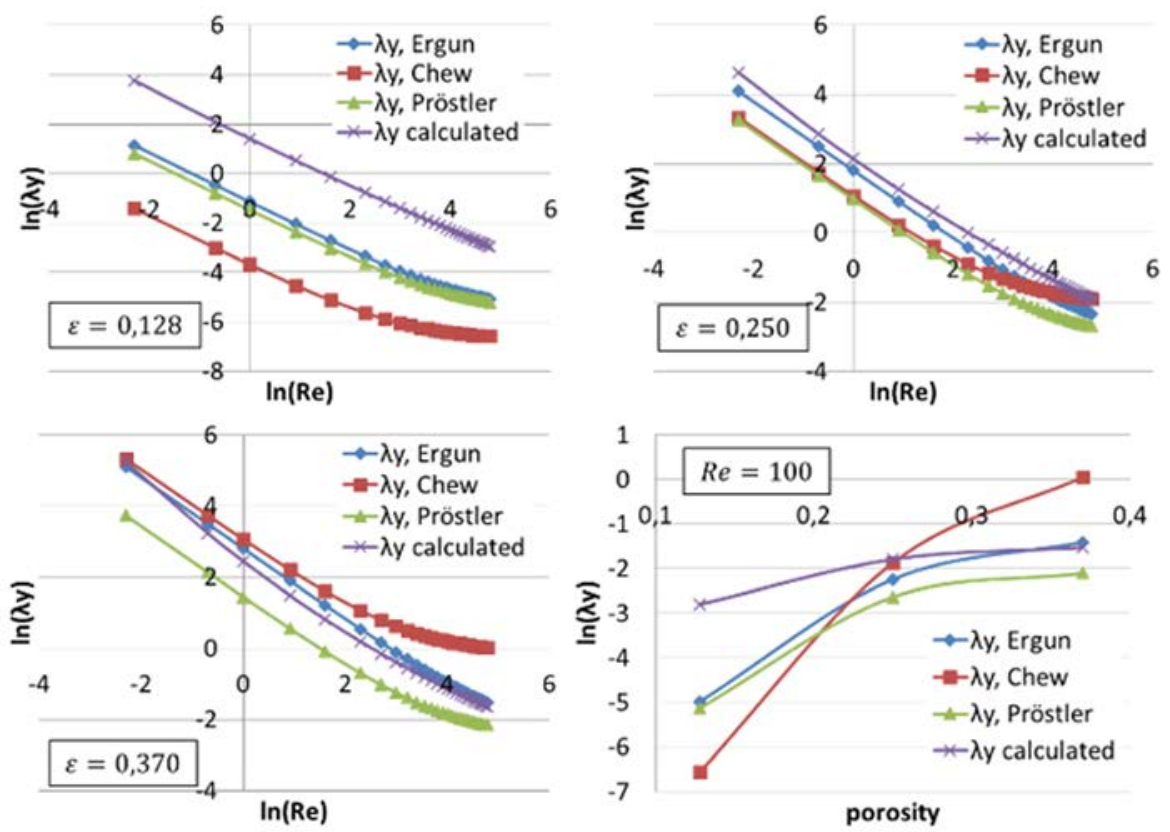

Fig. 16 Comparison of the calculated pressure drops along y axis with the literature $[6,9,11]$ 

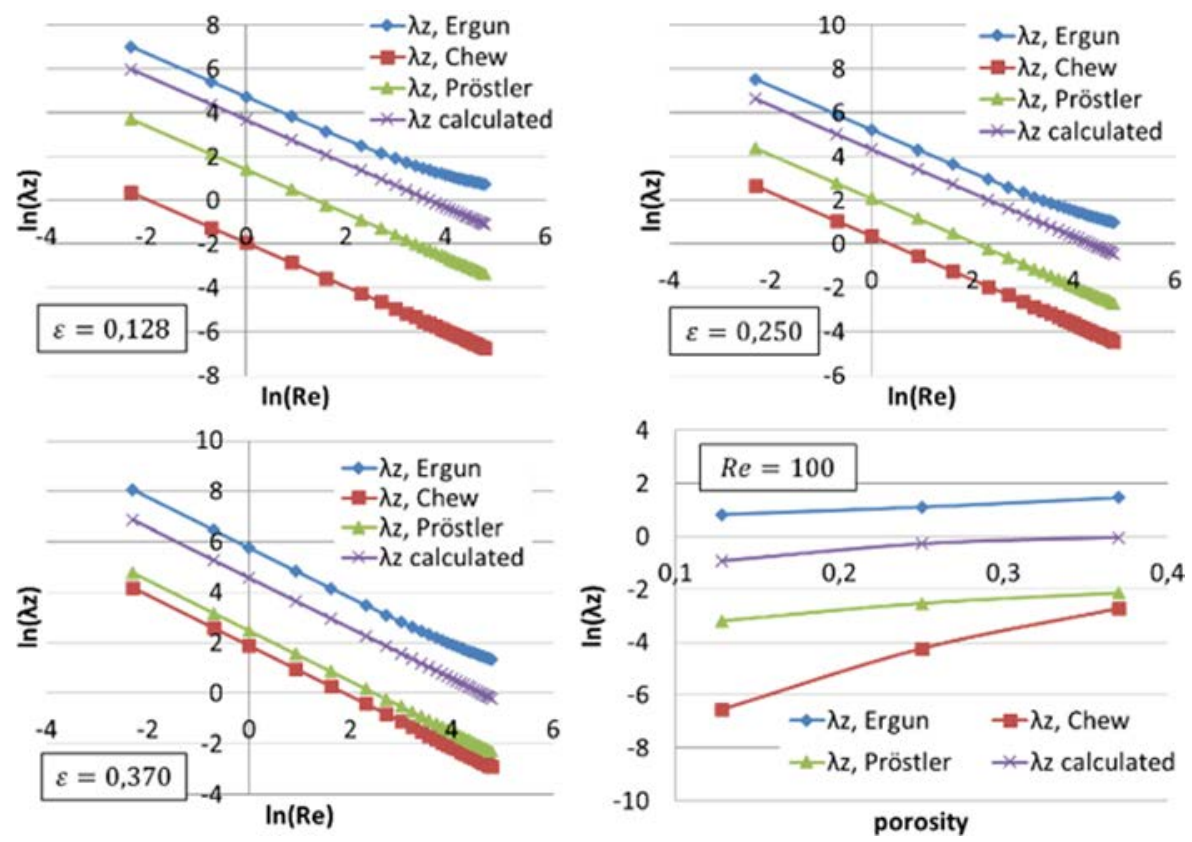

Fig. 17 Comparison of the calculated pressure drops along $z$ axis with the literature $[6,9,11]$

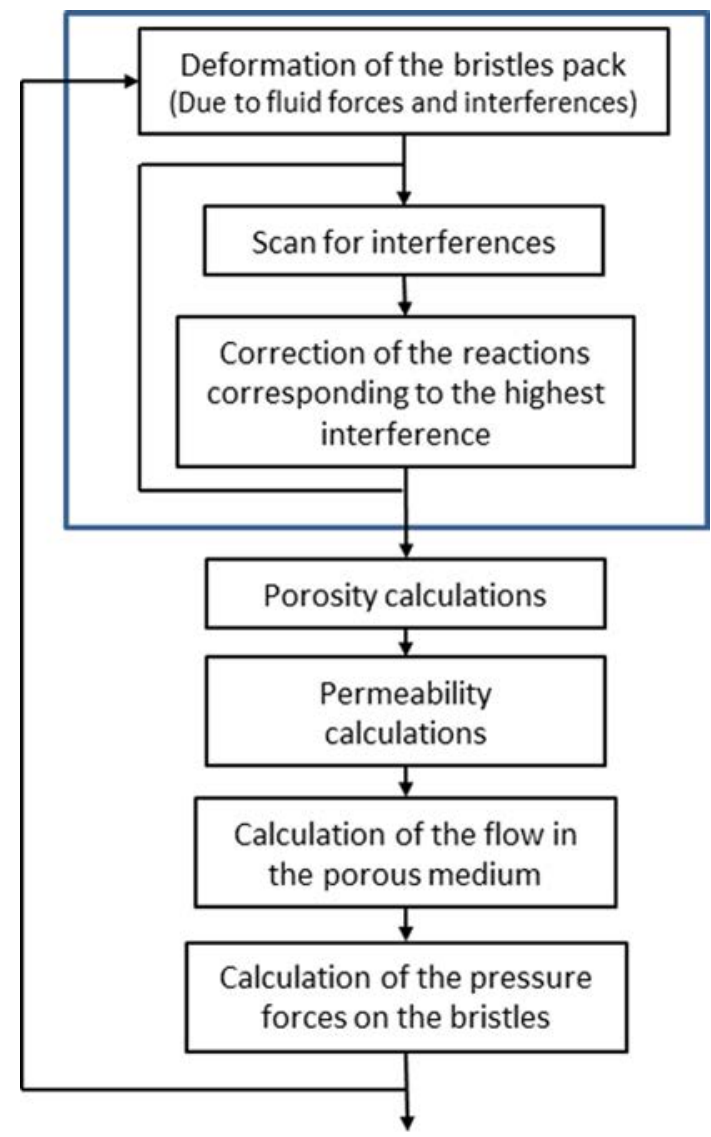

Fig. 18 Summary of the calculation method

A definition for the permeability can be deduced from Eqs. (12), (20), and (21)

$$
K(\varepsilon, \operatorname{Re})=\frac{\mu d_{h}}{\lambda(\varepsilon, \operatorname{Re}) \rho c_{v}^{2} u}
$$

Table 1 Data of the simulated seal [20]

\begin{tabular}{lc}
\hline \hline Material & Haynes 25 \\
\hline Young's modulus & $2.25 .10^{11} \mathrm{~N} / \mathrm{m}^{2}$ \\
Bristle's diameter & $0.0762 \mathrm{~mm}$ \\
Bristle's free height & $9.30 \mathrm{~mm}$ \\
Bristle's inclination angle & $45 \mathrm{deg}$ \\
Bristle length & $15.13 \mathrm{~mm}$ \\
Rotor diameter & $122.26 \mathrm{~mm}$ \\
Interference & $0.25 \mathrm{~mm}$ \\
Fence height & $1.25 \mathrm{~mm}$ \\
\hline \hline
\end{tabular}

$$
\operatorname{Re}=\frac{\rho d_{h} v}{\mu}=\frac{\rho d_{h} c_{v} u}{\mu}
$$

Pröstler [9] used general laws as Ergun's and Hagen-Poiseuille for the flow across and along the bristles. In the present approach, the permeability is evaluated from CFD calculations of the pressure drop in an array of cylinders representative for a brush seal. ${ }^{1}$ As depicted in Fig. 10, a different model was used for each principal direction of the brush: two-dimensional models for the $\mathbf{x}$ and $\mathbf{y}$ directions perpendicular to the bristles and a three-dimensional model for the $\mathbf{z}$ direction parallel to the bristles. The sizes of the domains are reduced by using symmetry conditions. The number of bristles in each of the two-dimensional models is chosen to avoid any influence of the boundary conditions. The pressure drop and fluid velocity are measured across the smallest periodic cell identified for each model (cells in light gray in Fig. 10). In the case of the three-dimensional model along the bristles, its length is selected large enough to avoid the influence of the boundary conditions. The pressure drop and the fluid velocity are measured again across a small length of the channel (Fig. 10).

The calculations were performed for different values of the porosity (from 0.111 to 0.370 ), obtained by varying the spacing of the bristles. Different values of Reynolds numbers defined by Eq. (23) were also considered by varying the pressure difference. All the calculations were made with water because the pressure drop

\footnotetext{
${ }^{1}$ The commercial code SolidWorks Flow Simulation [19] was used in the present work.
} 


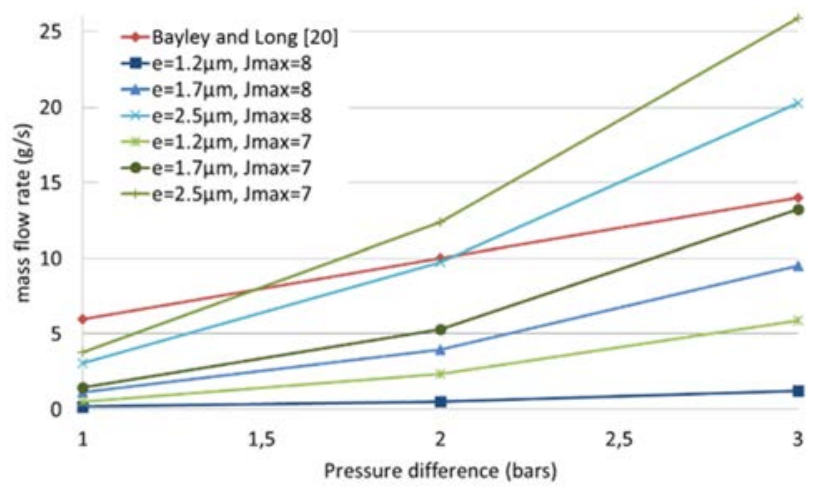

Fig. 19: Comparison of the calculated mass flow rates with the literature [20]

defined by Eq. (20) is valid only for incompressible fluids. Every calculation is a posteriori checked for verifying the laminar flow regime. $^{2}$ The nonconformal and unstructured mesh is automatically refined. The details of refined mesh are given in Fig. 11.

The obtained pressure drops are represented on the Figs. 12, 13, and 14 in logarithmic coordinates versus the Reynolds number. The results corresponding to $\mathbf{x}$ and $\mathbf{y}$ (transversal) directions can be approximated by second order polynomials. A straight line can approximate the pressure drop across the $\mathbf{z}$ (longitudinal) direction.

The CFD results can be also compared with the pressure drops stemming from the permeability used by Chew et al. [6,7], Ergun $[13,14]$, and Pröstler [9] for brush seal and porous medium modeling. These comparisons are presented in Figs. 15, 16 and 17 as a function of the Reynolds number and for three values of the porosity. Pressure drops versus porosity for a Reynolds number of 100 are also given in the lower left part of Figs. 15, 16 and 17. It can be observed that, for the lower value of the porosity, the calculated pressure drops in $\mathbf{x}$ and $\mathbf{y}$ directions are significantly higher than the ones obtained from the literature's permeability. For the medium and higher values of the porosity, the pressure drop values are relatively similar.

Finally, the complete iterative theoretical calculation is summarized by the flow chart depicted in Fig. 18.

\section{Comparisons With the Literature}

The results given by the theoretical model were compared with the experimental data published by Bayley and Long in 1993 [20]. The geometrical characteristics of the tested seal are given in Table 1.

Two additional parameters must be specified for the numerical simulations: the number of bristles in the direction of the flow, $\mathbf{y}$, and the roughness of the bristles. The Appendix shows how the total number of bristles in flow direction can be estimated if the density of the bristle pack is known. Following the results given in the Appendix, the calculations were performed for $j_{\max }=7$ or 8 bristles. Three bristle roughness values were considered: $1.2 \mu \mathrm{m}$, $1.7 \mu \mathrm{m}$ and $2.5 \mu \mathrm{m}$. The calculated mass flow rates are depicted in Fig. 19.

The two additional parameters have a significant impact. For a fixed $j_{\max }$ value, the mass flow rates obtained for small roughness are lower than the data measured in Ref. [20]. When the roughness increases, the calculated mass flow rates approaches the measured values. The number of bristles in the flow direction $j_{\max }$ has a comparable influence. For a fixed roughness value, the mass

${ }^{2}$ The separate analyses of the flow in $\mathbf{x}, \mathbf{y}$, and $\mathbf{z}$ directions are somewhat arbitrary but the errors should remain limited if the flow regime is laminar. A turbulent flow regime would strongly couple the three flow directions and would render meaningless their separate analysis.

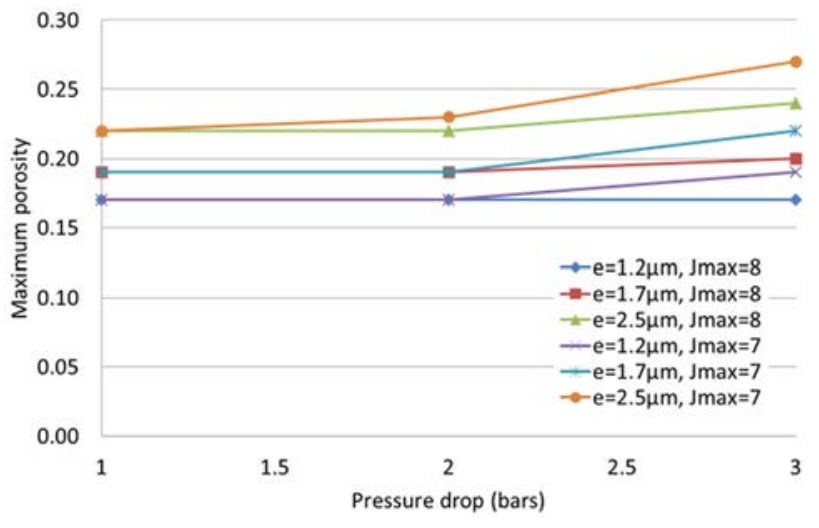

Fig. 20 Maximum brush porosity

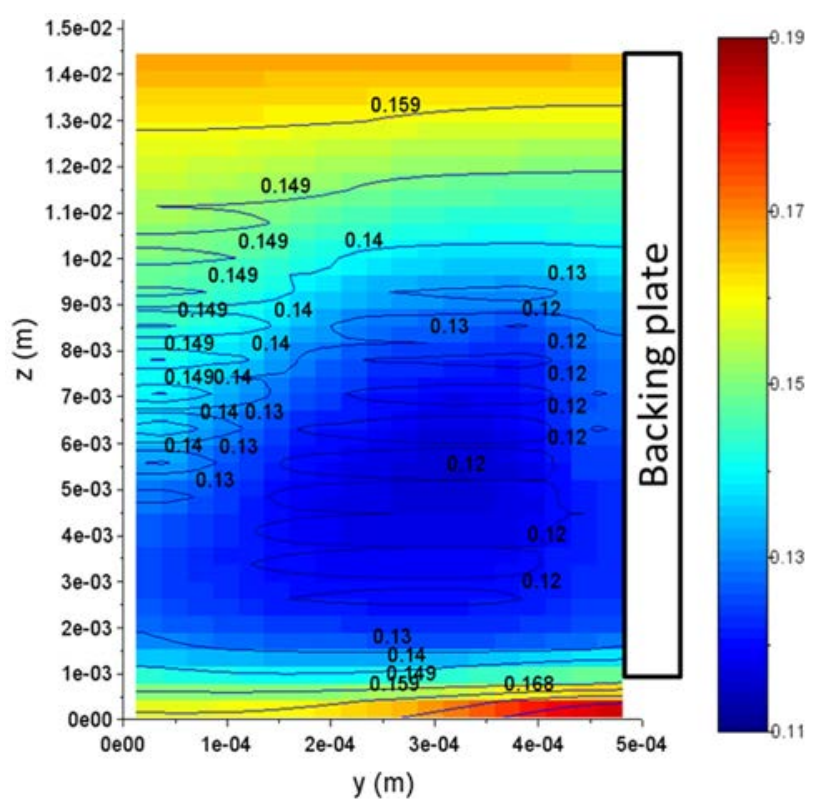

Fig. 21 Calculated porosity field in a section of the brush $\left(j_{\max }=7, e=1.2 \mu \mathrm{m}\right.$ and $\Delta P=3$ bar $)$

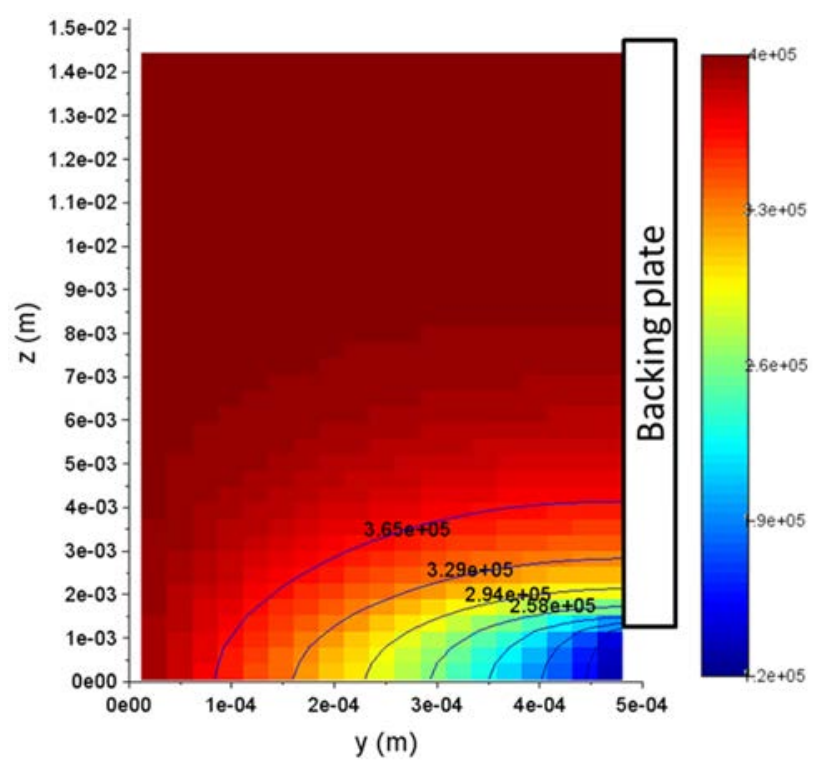

Fig. 22 Calculated pressure field in a section of the brush $\left(j_{\max }=7, e=1.2 \mu \mathrm{m}\right.$ and $\Delta P=3$ bar $)$ 


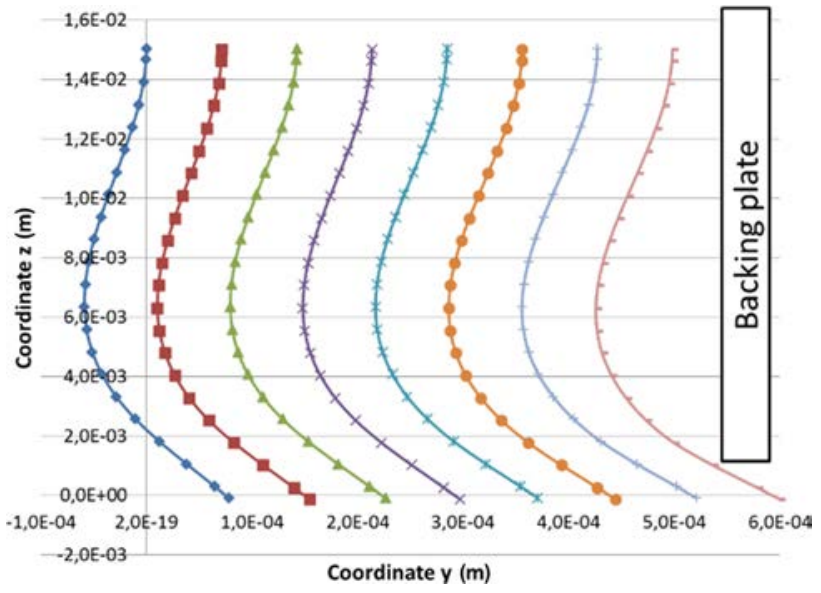

Fig. 23 Neutral line of the deformed bristles, in the $(y, z)$ plane

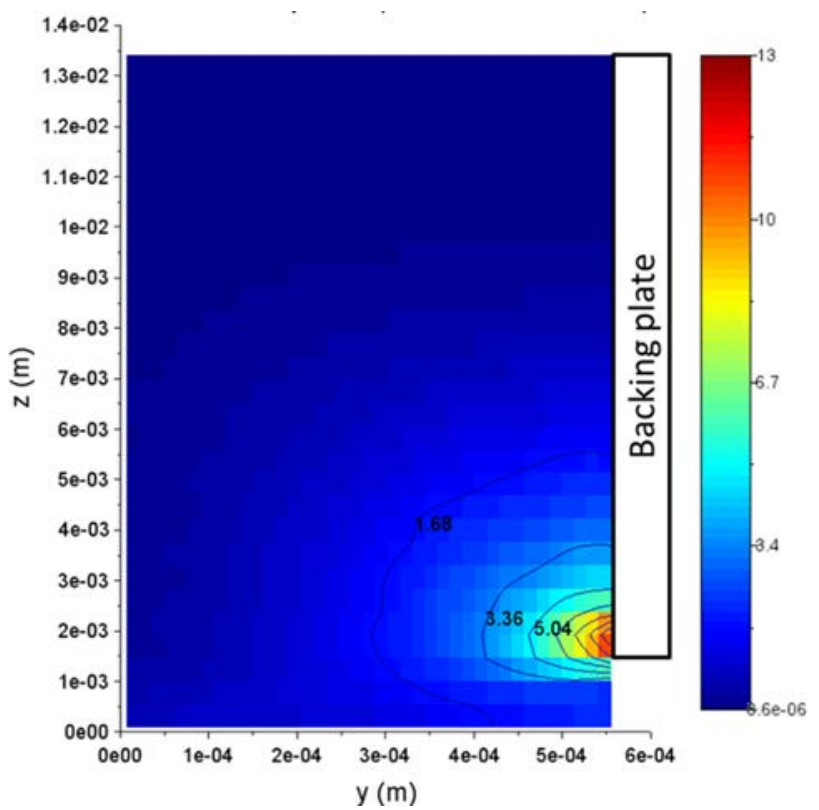

Fig. 24 Reynolds number in a section of the brush $\left(j_{\max }=8\right.$, $e=1.2 \mu \mathrm{m}$ and $\Delta P=1 \mathrm{bar})$

flow rates decrease with increasing the number bristles in the flow direction.

The results in Fig. 19 are mainly due to the porosity. Indeed, Fig. 20 depicts the maximum porosity stemming from all calculation cases. The comparison with Fig. 19 shows that the variation of the maximum porosity throughout the brush and the increasing of the mass flow rate with the pressure drop are correlated.

These results can be further explained by analyzing the correlation between the porosity, the pressure field and the bristle deformation. For example, Fig. 21 depicts the porosity field for one of the calculation cases and Fig. 22 shows the corresponding pressure field. The average porosity in Fig. 21 is close to 0.15 . This value is low compared to the porosity of $0.2 \ldots 0.3$ used by Pugachev and Helm in Ref. [21] and can explain the generally under estimated theoretical mass flow rate.

Figure 19 also shows that when the pressure difference increases, the calculated mass flow rate rises rapidly. A possible explanation is that the friction force between bristles is not taken into account when calculating the deformation of the bristles. Figure 23 shows that the part of the bristles situated in the fence height is strongly deformed by the pressure gradient. Actually, Fig. 22 shows that a large pressure drop occurs in a zone situated

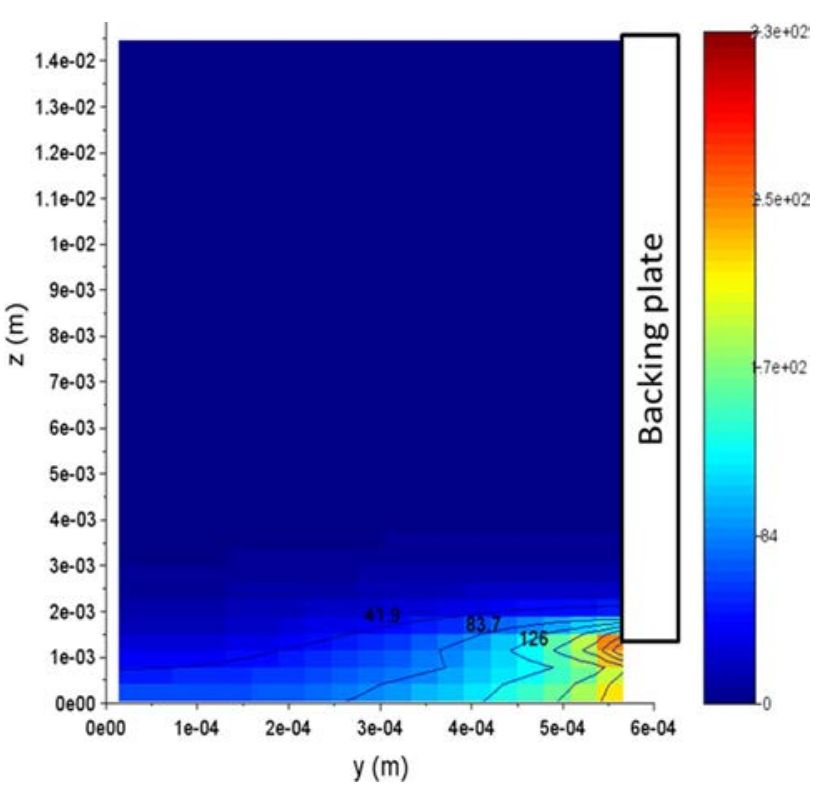

Fig. 25 Reynolds number in a section of the brush $\left(j_{\max }=8\right.$, $e=2.5 \mu \mathrm{m}$ and $\Delta P=3 \mathrm{bar}$ )

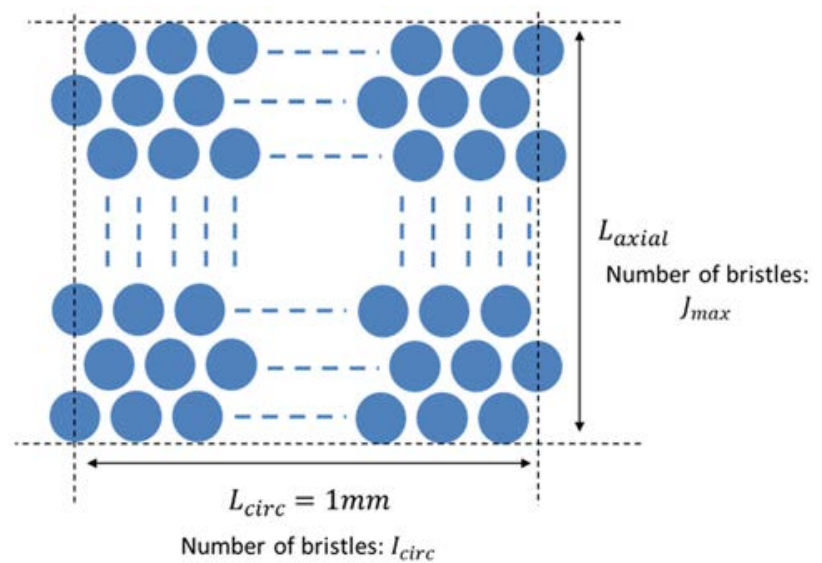

Fig. 26 Calculation of the number of bristles in the axial direction from the bristle pack density

close the lower part of the backing plate which explains why the bristles deform more in that zone and the porosity increases. However, the model is not adapted for taking into account the blowover effect that might occur under the backing plate.

In the case of a real seal, the friction between the bristles would prevent them from deforming that much. The friction would smoothen the variations of the porosity and would limit its increase.

The Reynolds number defined by Chilton and Colburn [18] and used by Gresham et al. [17] $\left(\mathrm{Re}=\rho D_{p} u / \mu\right)$ is plotted in a section of the brush for two extreme cases: an artificial roughness of 1.2 $\mu \mathrm{m}$ with a pressure difference of 1 bar (Fig. 24), and an artificial roughness of $2.5 \mu \mathrm{m}$ with a pressure difference of $3 \mathrm{bar}$ (Fig. 25). In both cases, the calculations are done with eight bristles in the axial direction.

In the first case, the Reynolds number is always lower than 13 and describes a flow that can be modeled using the Darcy's law, Eq. (12). In the second case, the Reynolds number reaches a maximum of 230, which completely justifies the use in Eq. (19) of a permeability $K$ that is a function of the porosity of the brush and of the local flow conditions as a way to take into account the inertia effects.

\section{Summary and Conclusions}

The paper presents a brush seal theoretical model based on a porous medium approach that does not rely on experimental 
calibration data. The porosity of the brush is obtained from a deformed bristle pack under interference constraints and its permeability is deduced from numerical calculations of the pressure drop generated by an array of representative cylinders.

The results given by the model were compared with the experimental data of Bayley and Long [20]. Although the model does not rely on experimental data, there are still two parameters that must be tuned: the number of bristles in the flow direction and their roughness. The calculations were then made for various values of these parameters, in order to underline their impact.

While showing good tendency, the calculated mass flow rates are generally under estimated. However, the mass flow rates tend to increase rapidly with the pressure drop. These two behaviors can be explained by the fact that friction forces are discarded in the bristle deformation model. This leads to a very compact deformed brush upstream of the back plate (with low porosities) and to important deformations of the bristles close to its lower corner (large porosities).

Taking into account the friction between bristles would smoothen the porosity variations inside the bristle pack.

\section{Acknowledgment}

The authors are grateful to Centre National d'Etudes Spatiales (CNES) and to Airbus Safran Launchers for supporting this work.

\section{Nomenclature}

$a, b=$ resistance coefficient

$c_{v}=$ coefficient defined in Eq. (21)

$e=$ bristle roughness $(\mathrm{m})$

$E=$ Young's modulus of elasticity $(\mathrm{Pa})$

$D=$ diameter $(\mathrm{m})$

$d_{h}=$ hydraulic diameter $(\mathrm{m})$

$D_{p}=$ characteristic diameter $(\mathrm{m})$

$\mathbf{f}=$ total deflection $(\mathrm{m})$

$\mathbf{f}=$ sum of the forces applied on the bristles $(\mathrm{N})$

$i=$ number of the column to which a bristle belongs

$i_{\max }=$ total number of bristles in the circumferential direction

$I_{z}=$ second moment of area of the bristle's section $\left(\mathrm{m}^{4}\right)$

$j=$ number of the row to which a bristle belongs

$j_{\max }=$ total number of bristles in the axial direction

$k=$ number of the node along a bristle

$k_{\max }=$ total number of nodes on a given bristle

$K=$ permeability $\left(\mathrm{m}^{2}\right)$

$L=$ bristle's length $(\mathrm{m})$

$P=$ pressure $(\mathrm{Pa})$

$q_{m}=$ mass flow rate $(\mathrm{kg} / \mathrm{s})$

$\mathbf{r}=$ correction of the forces applied to the bristles $(\mathrm{N})$

$R=\operatorname{radius}(\mathrm{m})$

$\mathbf{R}=$ forces applied to the bristles $(\mathrm{N})$

$\mathcal{R}=$ specific gas constant $\left(\mathrm{J} \mathrm{K}^{-1} \mathrm{~kg}^{-1}\right)$

$\mathrm{Re}=$ Reynolds number

$s=$ distance $(\mathrm{m})$

$S=$ surface between the bristles $\left(\mathrm{m}^{2}\right)$

$S_{f}=$ filtration surface $\left(\mathrm{m}^{2}\right)$

$T=$ temperature $(\mathrm{K})$

$u=$ filtration velocity $\left(\mathrm{m} / \mathrm{s}^{2}\right)$

$v=$ mean velocity of the fluid between the bristles $\left(\mathrm{m} / \mathrm{s}^{2}\right)$

$(x, y, z)=$ coordinates along the $(\mathbf{x}, \mathbf{y}, \mathbf{z})$ axis

$(\mathbf{x}, \mathbf{y}, \mathbf{Z})=$ local system of coordinates

$(X, Y, Z)=$ coordinates along the $(\mathbf{X}, \mathbf{Y}, \mathbf{Z})$ axis

$(\mathbf{X}, \mathbf{Y}, \mathbf{Z})=$ global system of coordinates

\section{Greek Symbols}

$\varepsilon=$ porosity at the $i j k$ node

$\zeta=$ deflection of the bristle in the $[\mathbf{y}, \mathbf{z}]$ plane (m)

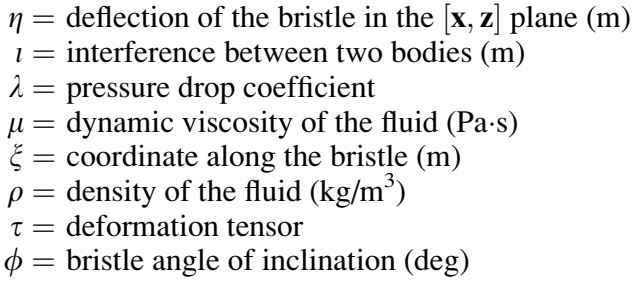

\section{Subscripts}

$i, j, k=$ node numbering

$x, y, z=$ related to the coordinate system

new $=$ new calculated value

old $=$ previous calculated value

\section{Superscripts}

backplate $=$ related to the back plate

bristles $=$ related to the bristles

contact $=$ related to the contact detection

fluid $=$ related to the fluid

$(n)=$ indicates the normal to a given bristle

rotor $=$ related to the rotor

\section{Appendix}

The number of bristles in the flow direction can be estimated only if the bristle pack density is known. For the test results of Bayley and Long, this information is not given in Ref. [20]. If we suppose a bristle pack density of 100 bristles $/ \mathrm{mm}$ and the bristle distribution depicted in Fig. 26, then the number of bristles can be roughly estimated as follows.

The number of bristles comprised in a millimeter of circumferential direction $\left(L_{\text {circ }}\right)$ is

$$
\begin{gathered}
L_{\text {circ }}=\left(i_{\text {circ }}-0.5\right)\left(D_{\text {circ }}+\text { spacing }\right) \\
I_{\text {circ }}=\frac{L_{\text {circ }}}{D_{\text {bristles }}+\text { spacing }}+\frac{1}{2}
\end{gathered}
$$

If the bristle pack is supposed completely compact, then spacing $=0$ and

$$
i_{\text {circ }}=14.8
$$

The brush density is

$$
\text { density }=i_{\text {circ }} j_{\max }
$$

Supposing a brush density of 100 bristles/mm of circumference yields

$$
j_{\max }=\frac{\text { density }}{i_{\text {circ }}}=6.75
$$

As the brush will never be completely compact, this calculated $j_{\max }$ is underestimated. The calculations are therefore performed for $j_{\max }=7$ and $j_{\max }=8$.

\section{References}

[1] Hendricks, R. C., Schlumberger, S., Braun, M. J., Choy, F., and Mullen, R. L., 1991, "A Bulk Flow Model of a Brush Seal System," ASME Paper No. 91-GT-325.

[2] Hendricks, R. C., Braun, M. J., Canacci, V., and Mullen, R. L., 1990, "Brush Seal in Vehicle Tribology," 17th Leeds/Lyon Symposium, Leeds, UK, Sept. 4-7.

[3] Chupp, R. E., Holle, G. F., and Dowler, C. A., 1991, "Simple Leakage Flow Model for Brush Seals," 27th Joint Propulsion Conference, Sacramento, CA, June 24-26.

[4] Chupp, R. E., and Holle, G. F., 1996, "Generalizing Circular Brush Seal Leakage Through a Randomly Distributed Bristle Bed," ASME J. Turbomach., 118(1), pp. 153-161.

[5] Braun, M. J., and Kudriavtsev, V. V., 1995, "A Numerical Simulation of Brush Seal Section and Some Experimental Results,” ASME J. Turbomach., 117(1), pp. 190-202. 
[6] Chew, J. W., Lapworth, B. L., and Millener, P. J., 1995, "Mathematical Modelling of Brush Seals," Int. J. Heat Fluid Flow, 16(6), pp. 493-500.

[7] Chew, J. W., and Hogg, S. I., 1997, "Porosity Modelling of Brush Seals," ASME J. Tribol., 119(4), pp. 769-775.

[8] Dogu, Y., 2005, "Investigation of Brush Seal Flow Characteristics Using Bulk Porous Medium Approach," ASME J. Eng. Gas Turbines Power, 127(1), pp. 136-144.

[9] Pröstler, S., 2005, "Modellierung und numerische Berechnungen von Wellenabdichtungen in Bürstenbauart," Ph.D. dissertation, Bochum Universität, Bochum, Germany.

[10] Guardino, C., and Chew, J. W., 2005, "Numerical Simulation of ThreeDimensional Bristle Bending in Brush Seals," ASME J. Eng. Gas Turbines Power, 127(3), pp. 583-591.

[11] Aksit, M. F., and Tichy, J. A., 1996, "A Computational Model of Brush Seal Bristle Deflection," AIAA Paper No. 1996-2909.

[12] Darcy, H. P. G., 1856, Les Fontaines Publiques De La Ville De Dijon, Victor Dalmont, Paris, France.

[13] Ergun, S., 1952, "Fluid Flow Through Packed Columns," Chem. Eng. Prog., 48(2), pp. 89-94.
[14] Ergun, S., and Orning, A. A., 1949, "Fluid Flow Through Randomly Packed Columns and Fluidized Beds," Ind. Eng. Chem., 41(6), pp. 1179-1184.

[15] Joseph, D., Nield, D., and Papanicolaou, G., 1982, "Nonlinear Equations Governing Flow in a Porous Medium," Water Resour. Res., 18(4), pp. 1049-1052.

[16] Jambhekar, V. A., 2011, "Forchheimer Porous-Media Flow ModelsNumerical Investigation and Comparison With Experimental Data," Master's thesis, Universität Stuttgart, Stuttgart, Germany.

[17] Gresham, T., Weaver, B., Wood, H., and Untaroiu, A., 2016, "Characterization of Brush Seal Permeability," ASME Paper No. GT2016-57910.

[18] Chilton, T. H., and Colburn, A. P., 1931, "Pressure Drop in Packed Tubes," Ind. Eng. Chem., 23(8), pp. 913-919.

[19] Solidworks, 2017, "Solidworks Flow Simulation," Dassault Systemes, VélizyVillacoublay, France, accessed Feb. 3, 2017, http://www.solidworks.fr/sw/ products/simulation/flow-simulation.htm

[20] Bayley, F. J., and Long, C. A., 1993, "A Combined Experimental and Theoretical Study of Flow and Pressure Distributions in a Brush Seal," ASME J. Turbomach., 115(2), pp. 404-410.

[21] Pugachev, A. O., and Helm, P., 2009, "Calibration of Porous Medium Models for Brush Seals," Proc. Inst. Mech. Eng., Part A, 223(1), pp. 83-91. 